\title{
Pembelajaran Legong Kuntir Berbasis E-Book
}

\author{
Ni Wayan Mudiasih, Rinto Widyarto \\ Program Studi Pendidikan Seni Pertunjukan, Fakultas Seni Pertunjukan, \\ Institut Seni Indensia Denpasar \\ Jalan Nusa Indah, Sumerta, Denpasar, Kota Denpasar, Bali 80235 \\ Tlp.089508993725, E-mail: wyn.mudiasih@gmail.com
}

\begin{abstract}
The island of Bali is strong with customs, traditions, culture and ancestral spirituality, upholding the value of Hinduism. The community is full of interest with a high art repertory, proven various types of dances exist in Bali, such as the variety of Legong dances (Lasem, Jobog, Nandir, Legod Bawa and Kuntir). In dance learning, various approaches, methods, and media are needed so that learners easily understand the material well. After learning stimulated learners become more interested, active and creative and fun The research method used is the Reseacrh and Development (RED) method with a procedural development model. Legong Kuntir Dance Based on E-Book can be used by teachers as a learning medium and used as learning materials by learners in SmK Negeri 3 Sukawati, especially in legong kuntir trai study.
\end{abstract}

Keywords: E-Book, Method, Legong Kuntir Dance.

\begin{abstract}
ABSTRAK
Pulau Bali yang kuat dengan adat, tradisi, budaya dan spritualitas leluhur, menjunjung tinggi nilai agama Hindu. Masyarakatnya penuh berkesenian dengan perbendaharaan seni yang tinggi, terbukti berbagai macam jenis tarian ada di Bali, seperti ragam tari Legong (Lasem, Jobog, Nandir, Legod Bawa dan Kuntir). Dalam pembelajaran tari diperlukan berbagai pendekatan, metode, dan media agar peserta didik mudah memahami materi dengan baik. Setelah pembelajaran peserta didik terstimulus menjadi lebih tertarik, aktif dan kreatif serta menyenangkan Metode penelitian yang digunakan yaitu metode Reseacrh and Development (R\&D) dengan model pengembangan prosedural. Tari Legong Kuntir Berbasis E-Book dapat dimanfaatkan guru sebagai media pembelajaran dan dimanfaatkan sebagai bahan belajar oleh peserta didik di SMK Negeri 3 Sukawati khususnya pada pmebelajaran tari Legong Kuntir.
\end{abstract}

Kata kunci: E-Book, Metode, Tari Legong Kuntir

\section{PENDAHULUAN}

Perkembangan teknologi yang begitu cepat, berpengaruh terhadap kehidupan manusia dan dunia pendidikan. Masa Pandemi saat ini teknologi mempengaruhi pe-rubahan perilaku kehidupan manusia, sehingga diperlukan upaya untuk mensikapi dan mengembangkan kinerja dalam mencapai tujuan tertentu. Pencapaian tujuan pembelajaran dalam bidang pendidikan menurut Syaefudin (2010, hlm. 6) inovasi pendidikan merupakan sebuah perubahan yang baru dan kualitatif berbeda yang diusahakan untuk meningkatkan pencapaian dalam bidang pendidikan. Secara tidak langsung inovasi dalam pendidikan sangat diperlukan guna mendorong individu mengembangkan cara berpikirnya. Inovasi 
dalam pendidikan, dapat membuka peluang bagi beberapa tenaga pengajar guna mengembangkan cara mengajar lewat teknologi. Teknologi saat ini dirasakan langsung dapat memberikan kemudahan serta efisiensi dalam berbagai bidang. Pengaplikasian teknologi terdapat beragam jenis, salah satunya ialah teknologi dalam pembelajaran. Teknologi pembelajaran sebagai sebuah bentuk penemuan ilmiah yang diaplikasikan kepada perangkat pembelajaran untuk mengefisiensikan proses pembelajaran di kelas (Silber, 1970, hlm. 35). Media ini dapat diaplikasikan ke dalam sebuah media berbasis E-Book pembelajaran yang baru pertama dikembangkan bagi Program Studi Pendidikan Seni Pertunjukan berkaitan pembelajaran dalam pendidikan tari.

Pengembangan media pembelajaran dilakukan secara bervariatif, mulai dari teks, gambar, audio, visual, dan audio visual. Rosmiati (2014, hlm. 271) menyatakan bahwa media dapat membangkitkan motivasi dan merangsang peserta didik dalam belajar, sehingga media pembelajaran sebagai penunjang belajar menjadi penting dalam memotivasi siswa dalam belajar. Pengembangan media tersebut dapat digunakan untuk menyampaikan materi, sumber bacaan yang bisa mobile dan juga sebagai materi praktik tari. Proses pembelajaran tari memerlukan berbagai macam pendekatan, metode, dan media agar peserta didik dapat menangkap materi dengan baik serta menstimulus peserta didik guna menjadi lebih sensitif dengan adanya rangsangan pengalaman agar ke depannya peserta didik menjadi individu yang lebih kreatif (Hidayat, 2006, hlm. 5). Mendasari hal tersebut pengembangan media berbasis E-Book pembelajaran tari Legong Kuntir, agar peserta didik mampu membangun pengetahuannya sendiri melalui media pembelajaran ini.

Pembelajaran tari Bali sudah banyak dikembangkan oleh berbagai lapisan masyarakat Bali, tetapi dengan media berbasis E-Book, belum banyak dikembangkan dan tentunya hasil pengembangan media berbasis E-Book ini dapat dengan mudah dibagikan kepada para pihak penyelenggara pendidikan tari. Analisis Kontekstual terhadap seni tari artinya fenomena seni itu dipandang dengan disiplin ilmu lain yang didominasi ilmu antropologi. Sesuai dengan bidangnya bersifat humaniora, yaitu ilmu yang ingin memahami segala aktivitas manusia dalam hubungan sosial budaya, maka ciri pendekatannya besifat holistik (Hadi, 2007, hlm. 97).

Pembelajaran tari di Bali sangat beragam, dimulai dari sanggar, lembaga pendidikan, dan institusi pendidikan seni. SMK Negeri 3 Sukawati dan SMK Negeri 5 Denpasar merupakan lembaga pendidikan yang menyelenggarakan pembelajaran praktik tari yang mengajarkan berbagai macam jenis tari mulai dari tari kreasi, tari klasik, hingga tari kekebyaran.

Berdasarkan wawancara I Gusti Ngurah Serama Semadi mengenai sejarah dan cerita Legong Kuntir di kediamannya, pada tanggal 9 Agustus 2021 dikatakan bahwa:

Jika membahas bagaimana sejarah Legong Kuntir, harus berbicara mengenai apa yang dimaksud dengan Legong terlebih dahulu, ka-rena Legong Kuntir merupakan salah satu jenis dari legong itu sendiri. Legong 
meru-pakan seni pertunjukan yang bernilai dra-matis dan multi karakter, yang dimaksud dengan multi karakter dimana tari Legong tersebut dipentaskan berdasarkan cerita, seperti halnya tari legong yang menceritakan kisah panji maka pada gerak-gerak tarinya terdapat unsur gerak yang memperlihatkan gerak raja itu sendiri.

Sedangkan kuntir berarti kuntara, kuntara yang berarti kera. Kera yang dimaksud adalah Subali dan Sugriwa, keduanya pada waktu kecil yang namanya Wang Bang dan Wang Kuning memperebutkan Cupu Manik Arta Gina (pemberian Bhatara Siwa) yang dimiliki oleh Dewi Anjani. Dewi Anjani merupakan putri dari Bhagawan Gotama dan Dewi Rinjani. Saat Dewi Anjani sibuk memainkan Cupu Manik Arta Gina, dilihatlah oleh Sugriwa dan Subali lalu mereka berusaha merebut Cupu Manik Arta Gina tersebut. Lalu Dewi Anjani membuangnya ke Telaga Sumala, kemudian mereka kembali bertaruh di dalam Telaga Sumala memperebutkan Cupu Manik Arta Gina tersebut. Sampai pada akhirnya Dewi Anjani berubah menjadi kera tetapi hanya kepalanya saja yang berubah. Selanjutnya Serama Semadi menjelaskan fungsi dan struktur Legong Kuntir dijelaskan sebagai berikut:

Fungsi Legong, sebagai hiburan sama halnya dengan legong lainnya. Struktur Tari Legong Kuntir yaitu pepeson, pengawak, Legod Ba-wa, pesiat, tetangisan, batel, pekaad. Tari Legong Kuntir menggunakan gamelan Se-marpegulingan sama halnya dengan tari Le-gong pada umumnya, alasan menggunakan gamelan Semarpegulingan dikarenakan ka-rakter suara gamelan Semarpegulingan ini sangat cocok dengan tari legong yang multi karakter. Tari legong kuntir jadi salah satu tari klasik yang dipelajari di SMK Negeri 3 Sukawati, karena SMK Negeri 3 Sukawati merupakan sekolah seni yang bertugas dalam pelestarian Tari klasik, salah satunya Tari Legong Kuntir (wawancara, 9 Agustus 2021).

Berdasarkan wawancara dengan seorang guru praktik tari Legong Ni Rai Sariadi, S.Sn dikatakan, bahwa tari Legong sangat penting diajarkan sebagai dasar penguasaan tari Bali (wawancara, 2 Juli 2021), untuk itu pembelajaran Legong dalam kurikulum SMK Negeri 3 Sukawati sangat beragam. Pengembangan media berbasis E-Book pembelajaran tari Legong ini mengambil salah satu materi Legong yang diajarkan, yaitu Legong Kuntir. Tari Legong pada umumnya memiliki lakon atau cerita yang disampaikan dalam pertunjukannya, begitu pula Legong Kuntir. Berdasarkan wawancara yang dilakukan di sanggar tari Bali Warini dengan pemilik sanggar yaitu Ni Ketut Arini, beliau merupakan salah satu maestro Legong di Kota Denpasar cerita Legong Kuntir sebagai berikut.

Legong Kuntir hampir sama dengan Legong Jobog, yaitu menggunakan cerita Subali dan Sugriwa, yang membedakan jika Legong Kuntir itu asal kata kitir-kitir yang artinya kecil jadi Legong Kuntir ceritanya Subali dan Sugriwa ketika masih kecil yang bernama Arya Kuning dan Arya bang. Ceritanya adik Arya Kuning dan Arya Bang yaitu Dewi Anjani punya Cupu Manik Astagina karena iri kakaknya ingin merebut Cupu Manik Astagina, tapi karena ayahnya kesal melihat Arya Bang dan Arya Kuning 
bertengkar lalu dibuang Cupu Manik ke telaga, langsung nyemplung berdua, makanya ada gerakan Ngelo di pesiat itu ceritanya lagi berenang (wawancara, 24 Agustus 2021).

Tari Legong Kuntir di rekonstruksi ulang pada tahun 1974-1975 dalam seminar yang diadakan oleh Proyek Pengembangan Sarana Wisata Budaya Bali. Seminar tersebut membahas tentang Legong Kuntir dan Legong Jobog, ketika itu ibu Ni Ketut Alit Arini merupakan salah satu peserta yang ikut berpartisipasi dalam rekonstruksi Legong Kuntir dan Jobog. Mengenai sejarah mengenai Legong kuntir seperti yang diungkapkan $\mathrm{Ni}$ Ketut Alit Arini bahwa:

Dahulu ketika saya kecil saya pernah mendengar tari Legong Kuntir tetapi tidak tahu Legong Kuntir itu seperti apa, tariannya bagaimana, yang saya ketahui hanya tari Legong Lasem karena saat itu memang di banjar kelandis punya sekeha tari Legong yang gamelannya di Pura Prajurit. Tetapi ketika tahun 1975-1976 ada program dari Proyek Pengembangan Sarana Wisata Budaya Bali, melakukan rekonstruksi ulang Legong Jobog, Legong Kuntir, dan beberapa bentuk Legong lainnya, karena sering sekali terjadi kekeliruan antara Legong Kuntir dan Legong Jobog. Ketika itu banyak orang yang berperan merekonstruksi tari Legong ini antara lain Anak Agung Raka Saba, Ni Ketut Reneng, I Gusti Bagus Nyoman Pandji, I Nyoman Rembang, I Wayan Sinti, dan saya menjadi penari Jobog waktu itu bersama ibu Agung Susilawati.

Berdasarkan wawancara dapat diidentifikasi bahwa bentuk tari Legong Kuntir yang biasa dipentaskan saat ini merupakan hasil rekonstruksi yang dilakukan oleh Yayasan Proyek Pengembangan Sarana Wisata Budaya Bali pada tahun 1974-1975. Pembuatan media berbasis E-Book dengan materi pembelajaran tari Legong Kuntir guna mendukung pengembangan pendidikan. Kondisi Pandemi Covid-19, menuntut pengembangan media pembelajaran berbasis E-Book melalui pembelajaran daring. Pembelajaran praktik dengan waktu singkat inilah yang kemudian dijadikan pedoman belajar tari Legong Kuntir untuk dapat diakses melalui media berbasis E-Book. Siswa dapat belajar di rumah secara mandiri, tanpa kecuali bagi masyarakat umum juga belajar mengakses melalui media berbasis E-Book ini.

Berdasarkan uraian di atas, pengembangan media berbasis E-Book ini sangat penting, mengingat saat ini dunia sedang mengalami Pandemi Covid-19, sehingga akses belajar secara face to face sangat sulit dilakukan. Hal ini diharapkan pengembangan media berbasis E-Book pembelajaran dapat menunjang pembelajaran tari Legong Kuntir, sebagai salah satu pengembangan media berbasis E-Book pembelajaran ini sangat penting melalui tahapa media berbasis E-Book pembelajaran sangat diperlukan dalam situasi Covid-19 yang tidak memungkinkan peserta didik untuk mendapat pembelajaran efektif; materi Legong merupakan pembelajaran penting untuk menunjang dasar tari Bali peserta didik. Media berbasis E-Book pembelajaran ini diujicobakan di salah satu sekolah menengah kejuruan seni yaitu SMK Negeri 3 Sukawati sebagai salah satu sekolah seni yang melaksanakan pembelajaran tari Legong Kuntir pada siswa kelas XII, sehingga 
diharapkan dapat membantu pembelajaran praktek bagi siswa. Permasalahan dari kajian ini membahas tentang pendidikan karakter melalui pembelajaran tari Legong Kuntir di SMK Negeri 3 Sukawati.

\section{METODE}

Metode yang digunakan dalam penelitian ini yaitu dengan metode Research and Development (R\&D) dengan model prosedural. Model prosedural merupakan model yang diadaptasi dari model menurut Borg and Gall yang mendeskripsikan langkah-langkah dalam merancang sebuah penelitian berupa produk yang dihasilkan sebagai upaya pencegahan masalah pendidikan dan pembelajaran. Penelitian Pembelajaran Legong Kuntir Berbasis E-Book memiliki tiga tahap pengembangan dalam proses pembuatan E-Book yaitu tahap Pra Pengembangan Penelitian, Pengembangan, dan Pasca Pengembangan.

Pra Pengembangan Penelitian, pada tahap ini peneliti mencari informasi dengan cara menganalisis kebutuhan menggunakan metode survey atau kualitatif sebagai awal kebutuhan pengembangan produk berupa E-Book. Survey dilakukan pada lokasi penelitian di SMK Negeri 3 Sukawati pada kelas Tari Legong. Teknik pengmpulan data dilakukan dengan cara observasi, wawancara dengan guru dan siswa SMK Negeri 3 Sukawati. Tahap brikutnyanya yaitu mengevaluasi hasil observasi serta menentukan perancangan pengembangan produk.

Hasil dari tahap pra pengembangan, kemudian mulai dilakukan perancangan produk dan pengembangan produk sesuai dengan produk yang digunakan pada peserta didik di SMK Negeri 3 Sukawati. Dalam pengembangannya ada beberapa lima kelengkapan tahapan yang harus diperhatikan yaitu Kelengkapan Identitas, Aspek Bahasa, Keluasaan Materi, Sistematika Evaluasi, dan Kejelasan Petunjuk.

Tahap terakhir yaitu tahap pasca pengembangan, mewujudkan bentuk E-Book berbasis Flip Profesional. Dari hasil analasis data-data yang didapat dilapangan baik melalui observasi maupun wawancara.

Perancangan media sangatlah penting, mengingat media teks, visual audio perlu memiliki penempatan navigasi yang tepat dan proposional sehingga penyampaian materi media visual-audio tersampaikan dengan baik dan tentunya menarik.

\section{HASIL DAN PEMBAHASAN}

Pembuatan video pembelajaran tari Legong Kuntir diawali dengan melakukan observasi dan melakukan tahap awal penelitian dengan cara need assement, yaitu dengan mengidentifikasi pembelajaran tari Legong di SMK Negeri 3 Sukawati. Pembelajaran tari Legong merupakan salah satu program pembelajaran mengenai tari klasik khususnya tari putri. Tari Legong yang diajarkan terdiri dari 7 jenis Legong dengan pembagian dua jenis Legong perjenjang kelas dan khusus di kelas XII ditambah satu materi Legong style Desa Saba. Materi Legong Kuntir merupakan materi yang diajarkan pada kelas XII, namun terkadang diganti dengan materi Legong Goak Macok dengan pertimbangan pihak kurikulum 


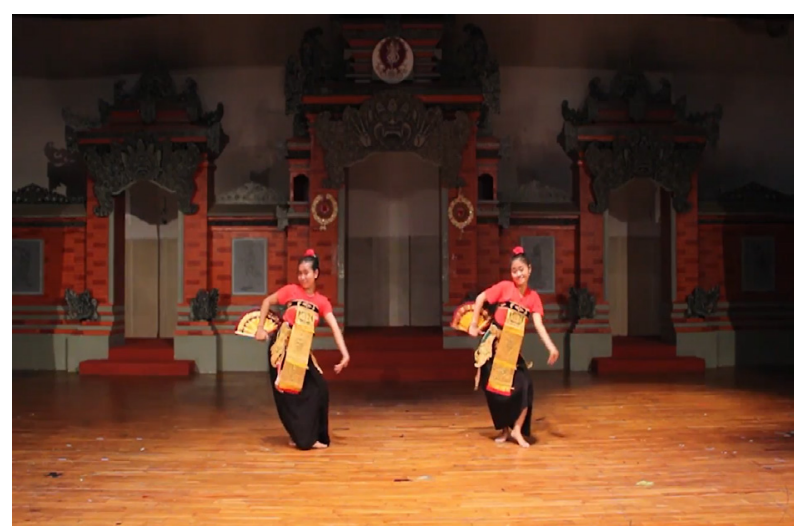

Gambar 1. Gerak-gerak dalam tari Legong Kuntir. (Sumber: Ni wayan Mudiasih, 2021)

dan guru mata pelajaran. Pembuatan video pembelajaran tari Legong Kuntir diperlukan untuk menunjang pembelajaran tari Legong Kuntir di SMK Negeri 3 Sukawati. Tahap selanjutnya adalah melakukan pengembangan, yaitu mengembangkan produk. Produk yang dikembangangkan menghasilkan media pembelajaran video yang berisi penjelasan tari Legong Kuntir mencakup, sejarah, fungsi tari, iringan tari, ragam gerak, dan struktur tari Legong Kuntir. Produk video pembelajaran tari Legong Kuntir hasil rekaman dan editing yang disajikan dalam E-Book.

Pengembangan video pembelajaran tari yang dikembangkan dengan pendekatan Reasearch and Development dimulai dengan melakukan tahap need assesment. Atas dasar observasi dan need assesment yang dilakukan, pengembangan video pembelajaran yang dikemas dalam media audio-visual untuk membantu pembelajaran tari klasik yaitu tari Legong dengan materi Legong Kuntir. Pengembangan video pembelajaran ini diharapkan mampu membantu proses pembelajaran tari Legong Kuntir. Media pembelajaran audio-visual tari Legong Kuntir yang berbentuk dalam kemasan DVD berupa tari Legong Kuntir secara utuh, Melihat fenomena ini maka dapat dikatakan bahwa wujud visual yang penuh makna tersebut merupakan suatu upaya untuk mengomunikasikan sebuah pesan (message) (Larry, Jo-dog, Santosa, 2016, hlm. 30). Adapun isian produk diawali dari pengumpulan materi pendukung, pembuatan media pembelajaran video tari Legong Kuntir ini terdiri dari video ragam gerak, video tata rias, video tata busana, dan video pementasan secara keseluruhan. Sedangkan untuk pembelajaran terdiri dari video ragam gerak, video struktur gerak dan pola lantai.

Legong Kuntir merupakan salah satu bentuk tari Legong yang kemunculannya hampir sulit ditentukan kapan diciptakan dan siapa yang menciptakan, sehingga tari ini merupakan tari anonim, atau tidak diketahui penciptanya. Guna menelusuri sejarah mengenai Legong Kuntir, peneliti melakukan wawancara kepada salah satu maestro tari Bali yaitu Ni Ketut Arini. Dalam wawancara tersebut beliau mengatakan:

Dahulu ketika saya kecil saya pernah mendengar tari Legong Kuntir tetapi tidak tahu Legong Kuntir itu seperti apa, tariannya bagaimana, yang saya ketahui hanya tari Legong Lasem. Tetapi ketika tahun 1975-1976 ada program dari Proyek Pengembangan Sa-rana Wisata Budaya Bali, melakukan rekons-truksi ulang Legong Jobog, Legong Kuntir, dan beberapa bentuk Legong lainnya, karena sering sekali terjadi kekeliruan antara Legong Kuntir dan Legong Jobog. Ketika itu banyak orang yang berperan merekonstruksi tari Legong ini antara lain Anak Agung Raka Saba, Ni Ketut Reneng, I Gusti Bagus Nyoman Pandji, I Nyoman Rembang, I Wayan Sinti, dan saya menjadi penari Jobog waktu itu bersama ibu Agung Susilawati (wawancara, 28 Oktober 2020). 
Berdasarkan wawancara tersebut dapat diidentifikasi bahwa bentuk tari Legong Kuntir yang biasa dipentaskan saat ini merupakan hasil rekonstruksi yang dilakukan oleh Yayasan Proyek Pengembangan Sarana Wisata Budaya Bali pada tahun 1974-1975. Dalam pementasannya tari Legong Kuntir memiliki struktur tari yang lengkap. Struktur tari Legong Kuntir berdasarkan wawancara dengan $\mathrm{Ni}$ Ketut Arini (wawancara 28 Oktober 2020) dan Ibu Ni Rai Sariadi (20 Oktober 2020) beliau mengatakan ada 7 struktur yaitu: pengawit; pengawak; gegaboran/ pengecet/ angkat-angkatan; pengetog; pesiat; tetangisan; pekaad. Struktur tari dibagi perbabak sesuai pakem tari Legong yang asli sesuai cerita yang dibawakan.

Tari Legong Kuntir berfungsi sebagai tari hiburan profan atau Balih-Balihan, hal ini terdapat dalam konsep pementasannya yang menonjolkan sisi profan atau hiburan estetis, meskipun dalam masyarakat Bali tari Legong dilestarikan dengan memasukan unsur sakral ke dalam pementasannya, Legong pada dasarnya adalah bentuk pementasan yang dapat dilakukan dimana saja, kapan saja hampir tanpa ikatan waktu tertentu (Dibia, 2004, hlm. 4).

Bali mempunyai berbagai arti, antara lain: kembali, persembahan, sesaji, kurban untuk mohon pengampunan, sungguh, pasti, dan yang lainnya yang sepadan dengan kata tersebut, sedangkan Dwipa berarti pulau (Dewi, 2016, hlm. 425). Bali sebagai salah satu pulau yang masih memegang teguh tradisi dan kebudayan nenek moyangnya dengan menjunjung tinggi nilai-nilai ajaran agama Hindu. Masyarakat Bali dengan berkesenian memiliki perbendaharaan seni yang tinggi.
Masyarakat pada umumnya menghabiskan waktunya untuk memenuhi kepuasan atas rasa keindahan (keindahan natural/buatan manusia). Sejatinya kesenian sebagai ungkapan rasa keindahan merupakan kebutuhan manusia secara luas. Kesenian tidak hanya dimiliki oleh kalangan menengah ke atas atau kalangan menengah ke bawah, melainkan juga menjadi kebutuhan orang miskin atau orang yang hidup dalam serba kesulitan.

\section{SIMPULAN}

Pembuatan E-Book tari Legong Kuntir menggunakan metode penelitian Research and Development dengan model pengembangan Model prosedural merupakan model yang diadaptasi dari model menurut Borg and Gall dengan mendeskripsikan langkahlangkah dalam merancang sebuah penelitian berupa produk yang dihasilkan sebagai upaya pencegahan masalah pendidikan dan pembelajaran. Penelitian Pembelajaran Legong Kuntir Berbasis E-Book memiliki tiga tahap pengembangan dalam proses pembuatan E-Book yaitu tahap Pra Pengembangan Penelitian, Pengembangan, dan Pasca Pengembangan.

Pembuatan E-Book tari Legong Kuntir diawali dengan pembuatan video pembelajaran dengan cara need assement. Mengidentifikasi pembelajaran tari Legong di SMKNegeri 3 Sukawati sebagai satu program pembelajaran tari klasik di kelas XII. Materi Legong Kuntir dengan pertimbangan pihak kurikulum dan guru mata pelajaran. Pembuatan video pembelajaran tari Legong Kuntir diperlukan untuk menunjang pembelajaran tari Legong 
Kuntir dan menjadi bahan/sumber pada penyusunan E-Book. Tahap produk yang dikembangangan menghasilkan media pembelajaran video berisi penjelasan tari Legong Kuntir mencakup (sejarah, fungsi tari, iringan tari, ragam gerak, dan struktur tari Legong Kuntir). Selanjutnya produk video pembelajaran tari Legong Kuntir hasil rekaman dilakukan editing dan disajikan dalam E-Book.

\section{DAFTAR PUSTAKA}

A, Doni Koesoema. (2007). Pendidikan Karakter: Mendidik Anak di Zaman Global. Jakarta: Grasindo.

AECT. (2004). The Definition And Domain Of The Field. Washington, D.C: Association for Educational Communication and Technology.

Amri, Sofan. (2013). Pengembangan \& Model Pembelajaran dalam Kurikulum 2013. Jakarta: Prestasi Pustaka

Anurrahman. (2013). Belajar dan Pembelajaran. Bandung: Alfabeta

Arini, Ni Ketut. (2012). Teknik Tari Bali. Denpasar: Yayasan Tari Bali Warini.

Bandem, I Made, dkk. (2018). Kamus Seni Tari Bali. Denpasar: Balai Bahasa Bali.

Borg dan Gall. (2003). Education Research. New York: Allyn and Bacon.

Budhisantoso, S. (1991). Kesenian dan Kebudayaan di Indonesia. Surakarta: STSI-PRESS.

Charles M. Reiguth dan Martin Barbara. (1999). Affective Education and the Affective Domain: Implicaton For Intructional Design Theorist an Models Volume II. New Jersey: Lawrence Erlbaum Associates,inc.

Daryanto. (2013). Media Pembelajaran. Yogyakarta: Gava Media.
Dibia, I Wayan, dkk. (1977/1978). Pengantar Karawitan Bali. Denpasar: Proyek Peningkatan/ Pengembangan ASTI Denpasar.

Dibia, I Wayan. (1999). Selayang Pandang Seni Pertunjukan Bali. Bandung: Masyarakat Seni Pertunjukan Indonesia

Dibia, I Wayan. (2004). Pragina : Penari, Aktor, dan Pelaku Seni Pertunjukan Bali. Malang: Sava Media.

Dibia, I Wayan. (2013). Puspasari Seni Tari Bali. Denpasar: UPT Penerbit ISI Denpasar.

Djayus. (1980). Teori Tari Bali. Denpasar: CV Sumber Mas Bali.

Djelantik, A.A.M. (1990). Estetika Sebuah Pengan tar. Bandung: Masyarakat Seni Pertunjukan.

Fitri, Agus Zaenul. (2012). Pendidikan Karakter berbasis Nilai dan Etika di Sekolah. Jogjakarta: Ar - Ruzz Media

Hamalik, Oemar. (2001). Media Pendidikan. Bandung: PT. Citra Aditya Bakti Aksara Haryati, Ni Made. (2014). Tesis. "Peranan Ni Ketut Reneng Dalam Pelestarian Tari Legong di Denpasar. Denpasar: ISI Denpa-sar.

Julianto, I Nyoman., Jodog, I Made., Santosa, Iman. (2016). Nilai Interaksi Simbol Tra-disi Dalam Wujud Pelinggih Pada Ruang Publik. Panggung: 26 (1), 25-34.

Kesuma, Dharma dkk. (2011). Pendidikan Karakter. Bandung: PT Remaja Rosdakarya.

Munadhi, Yudhi. (2013). Media Pembeljaran. Jakarta: Refrensi

Nilawati, Ni Kadek. (2020). “Pengembangan Video Pembelajaran Tari Legong Gadung Melati Style Desa Saba di SMK Negeri 3 Sukawati Gianyar". Skripsi. Denpasar: ISI Denpasar.

Pandji, IGusti Bagus Ngurah, dkk. (1974/1975). Perkembangan Tari Legong Keraton. Denpasar: Proyek Pengembangan Sarana Wisata Budaya Bali.

Prihartiningrum, Rizki. (2014). Perkembangan Tari Legong Keraton Gaya Peliatan Ta-hun 1928-1954 dalam AVATARA e-Journal Pendidikan Sejarah 2 (2), Juni 2014. 
Purnama, Dewi Anggraeni. (2016). Komodifikasi Tari Barong di Pulau Bali Seni berdasarkan Karakter Pariwisata. Panggung: 26 (3), 423-433

Hidayat, Robby (2012). Wawasan Seni Tari. Malang: Banjar Seni Gantar Gumelar.

Rosmiati, A. (2014). Teknik Stimulasi dalam Pendidikan Karakter Anak Usia Dini melalui Lirik Lagu Dolanan. Jurnal Resital, 15 (1)

Sadiman, Arif, dkk. (2005). Media Pendidikan: Pengertian, Pengembangan dan Pemanfaatannya. Jakarta: PT Raja Grafindo Pesada

Salam, Burhanuddin. (2011). Pengantar Pedagogik [Dasar-Dasar Ilmu Mendidik]. Jakarta : Rineka Cipta

Satrianingsih, Aline Rizky Oktaviari. (2013). "Pengembangan Video pembelajaran Interaktif Tari Melinting Untuk SMA". Skripsi. Yogyakarta: Universitas Negeri Yogyakarta

Sugiyono. (2014). Metode Penelitian Kualitatif, Kuantitatif, dan RED. Bandung: Alfabeta.

Sugiyono. (2014). Metode Penelitian Pendidikan Pendekatan Kualitatif, Kuantitatif, dan RED. Bandung : Alfabeta

Suharti, Mamik. (2013). Tari Ritual dan Kekuatan Adikodrati. Panggung: 23 (4), 425-431

Sustiawati, Ni Luh. (2008), “Pengembangan Manajemen Pelatihan Seni tari Multikultural Berpendekatan Silang Gaya Tari Bagi Guru Seni Tari Sekolah Menengah Pertama Negeri di Kota Denpasar", Disertasi yang tidak dipublikasikan. Universitas Negeri Malang.

Sutarman. (2012). Pengantar Teknologi Informasi. Jakarta : PT Bumi Askara.

Syaefudin, Udin. (2010). Inovasi Pendidikan. Bandung: ALFABETA.

Tafonao, Talizaro. (2018). Peranan Media Pembelajaran dalam Meningkatkan Minat Belajar Mahasiswa. Jurnal Komunikasi Pendidikan, 2 (2), Juli 2018. Yogyakarta: TT KADESI Yogyakarta.

Warsita, Bambang. (2008). Teknologi Pembelajaran Landasan \& Aplikasinya. Jakarta : Rineka Cipta.
I Gusti Agung Gede Mega Perbawa, Made Sudarma, I Made Arsa Suyadnya. (2014). Aplikasi Pembelajaran Gerakan Dasar Tarian Bali Dengan Simulasi Model 3d Berbasis Android dalam E-Journal SPEKTRUM 1 (1) Desember 2014.

Y. Sumandiyo Hadi. (2007). Kajian Tari: Teks dan Konteks. Yogyakarta: Pustaka Book Publisher 